\title{
The New Governance Era: Implications for Collaborative Conservation and Adaptive Management in Department of the Interior Agencies
}

\author{
KIRSTEN M. LEONG, ${ }^{1}$ DAVID P. EMMERSON, ${ }^{2}$ \\ AND REBECCA (RUDI) BYRON ${ }^{3}$ \\ ${ }^{1}$ Biological Resource Management Division, National Park Service, Fort Collins, \\ Colorado, USA \\ ${ }^{2}$ Office of Collaborative Action and Dispute Resolution, Department of the \\ Interior, Washington, D.C., USA \\ ${ }^{3}$ Department of Urban Affairs and Planning, Virginia Tech (National Capital \\ Region), Blacksburg, Virginia, USA
}

\begin{abstract}
The U.S. Department of the Interior (DOI) manages one-fifth of the land in the United States, including public lands administered by the National Park Service, U.S. Fish and Wildlife Service, and Bureau of Land Management. Federal agencies have included public input in decision-making since the Administrative Procedure Act in 1946, with varying degrees of effectiveness. Recently, policy and reporting directives have broadened to include possibilities for collaborative conservation. Many disciplines are identifying this rise in collaboration as a new era of governance. Yet, this philosophy has not yet diffused widely throughout DOI agencies in practice. We explored how these concepts might become institutionalized more broadly in DOI agencies by examining legal and policy considerations with respect to governance paradigms and conducting pilot interviews with key informants. As large-scale societal changes continue to affect the way people experience and value public lands, effectively incorporating collaborative conservation will be increasingly important in management.
\end{abstract}

Keywords governance, public engagement, public input, public participation

Over the past few decades, natural resource management has entered an "era of turbulence" (Lachapelle, McCool, \& Patterson, 2003, p. 473) characterized by controversy and conflict surrounding agency actions. One root of this controversy is the growing recognition of inherent uncertainty in managing ecological systems, especially in the face of global stressors such as climate change. In addition, managers more regularly face problems that cross agency jurisdictions and affect stakeholders with widely diverse views and values. Natural resource problems are being recognized as ill-structured, "wicked," or "messy" problems that are logically complex but also have no clear right or wrong answers because the problem is seen differently through various stakeholder lenses (Allen \& Gould Jr., 1986; Lachapelle et al., 2003; Rittel \& Webber, 1973). As a result, scholars and practitioners have identified emerging shifts in management paradigms from a scientific or

Address correspondence to Kirsten M. Leong, Human Dimensions Program Manager, Biological Resource Management Division, National Park Service, 1201 Oakridge Drive, Suite 200, Fort Collins, CO 80525, USA. E-mail: kirsten_leong@nps.gov 
mechanistic worldview to an ecosystem, collaborative, and adaptive worldview (e.g., see Ansell \& Gash, 2008; Brunner et al., 2005; Robertson \& Choi, 2010). These new paradigms are associated with changes in governance from top-down models to more participatory, collaborative models. While abundant research on collaborative governance identifies characteristics of successful case studies, potential best practices, and alternate metrics, we wanted to explore how these concepts might become institutionalized more broadly in U.S. Department of the Interior (DOI) agencies.

The DOI manages approximately one-fifth of the land in the United States, including public lands administered by the National Park Service (NPS), U.S. Fish and Wildlife Service (FWS), and Bureau of Land Management (BLM). These lands provide essential habitat for wildlife survival and reproduction; sources of clean water and other ecosystem services; opportunities to learn about and experience our nation's natural and cultural resources; and opportunities for economic endeavors, such as tourism, and mineral and timber extraction. Each agency has a specific mission that defines its purpose with respect to natural resource management, yet these lands all are managed in the public trust, to be preserved by the government for current and future generations (Sax, 1970).

Given this context, federal land managers must make decisions that fulfill conservation mandates and satisfy the myriad publics to whom they are responsible. Previous eras relied on scientific management principles and technocratic decision-making, which emphasize fixed goals, stable systems, reductionism, certainties, prediction and control, competition among interests, and expert authority governance (Brunner et al., 2005; Robertson \& Choi, 2010). Federal land management focused on lands within jurisdictional boundaries, functionally treating these areas as islands of protected habitat This analogy began to break down with increased recognition of global stressors, acknowledgment of the interdependence between ecological and social systems within and outside protected areas, and the rise of ecosystem-based management and systems thinking (Layzer, 2008; Robertson \& Choi, 2010). As a result, agencies have begun to more fully embrace ecosystem management at a landscape (vs. organizational unit) scale, and adaptive management. At the same time, societal changes, such as the environmental movement of the 1960s and '70s, heightened distrust of government, and democratization of information, resulted in increased pressure from the public for opportunities to be involved in decision-making, intractable conflicts over environmental issues, and creative experiments to engage the public more collaboratively (Lauber, Decker, \& Knuth, 2008; Wondolleck \& Yaffee, 2000).

Robertson and Choi (2010) argue that these changes collectively signal a transition from the modern era to a new era in governance, where governance refers to the interactions among structures, processes, and traditions that determine how power and responsibilities are exercised, decisions are made, and citizens or other stakeholders are included in collective decisions (Ansell \& Gash, 2008). Researchers are examining this shift under many frameworks, including new governance (Bingham, Nabatchi, \& O'Leary, 2005), experimentalist governance (de Burca, 2010), collaborative governance (Ansell \& Gash, 2008), ecological governance (Robertson \& Choi, 2010), and adaptive governance (Brunner et al., 2005). Regardless of terminology, these analyses converge on common elements of a new governance era, including interdependence, decentralization, horizontal networks, cooperation, common interests, shared beliefs, transparency, trust, relationship building, learning, flexibility, and adaptation.

For reasons explained below, we use the term "public engagement" to refer to this new form of governance and adopt the definition put forth by Ansell and Gash (2008): "A governing arrangement where one or more public agencies directly engage non-state stakeholders in a collective decision-making process that is formal, consensus-oriented, and 
deliberative and that aims to make or implement public policy or manage public programs or assets" (p. 544). While recent legal and policy directives indicate this approach is gaining currency to the extent possible within current frameworks, previous research (Leong \& Decker, 2009) and professional experience indicate this philosophy is not yet widely practiced in DOI. To improve the adoption of collaborative conservation more broadly in DOI agencies, we took two approaches. We first examined legal and policy considerations to determine the extent to which they reflect changing governance paradigms. Second, we conducted pilot interviews with key informants to identify more specific lines of inquiry that could yield a suite of priority activities for DOI agencies.

\section{Legal and Policy Considerations}

Leong, Decker, Lauber, Raik, and Siemer (2009) identified three historic governance models regarding public involvement in government decision-making (Figure 1). In top-down governance, the agency's role is to keep the public informed of management decisions. The agency simply asserts its statutory authority over resources and does not actively seek public involvement. In public input governance, agencies actively seek input from individual stakeholders or groups of stakeholders, but the focus is on the agency learning about stakeholder interests rather than stakeholders learning from each other. Public engagement

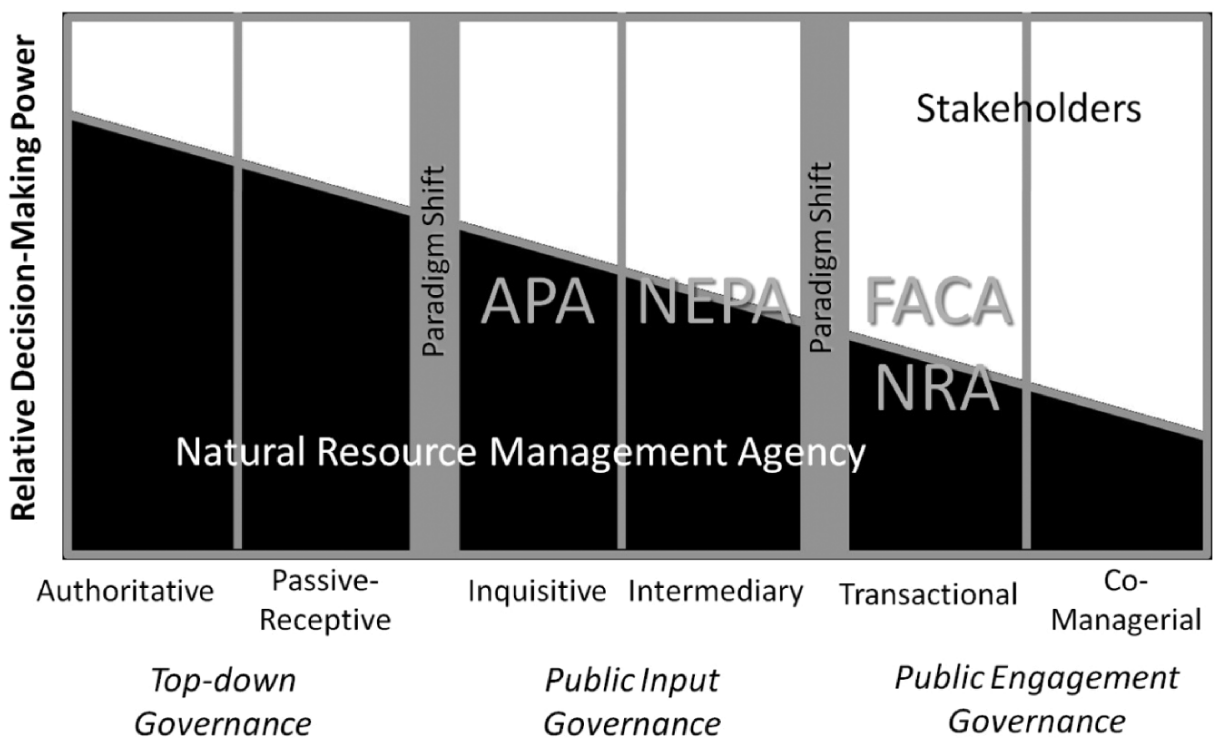

Approach to Public Involvement

Figure 1. Governance models for public participation and relative decision-making power. White indicates relative decision-making power of stakeholders, black of natural resource management agency. Each governance model encompasses multiple approaches to public involvement, described in detail in Leong et al. (2009). Shifts between governance models represent different paradigms regarding appropriate roles of agencies and stakeholders in public participation. Legal authorities corresponding to various approaches are indicated in gray text: APA $=$ Administrative Procedure Act, NEPA = National Environmental Policy Act, FACA = Federal Advisory Committee Act, NRA $=$ Negotiated Rulemaking Act. 
governance emphasizes dialogue and mutual learning between agencies and multiple stakeholders to identify common interests, broaden the decision space, and develop sustainable alternatives. In this framework, public engagement governance corresponds to collaborative governance as used by Ansell and Gash (2008), while more explicitly co-managerial approaches constitute special cases of public engagement.

Much of the literature reviewed in the introduction does not distinguish between the first two governance models, often referring to public input processes as examples of top-down governance. We agree that many public input opportunities are not as inclusive as they could be, but argue that legal requirements to include public input signal a conceptual departure from top-down governance. The Administrative Procedure Act (APA, 1946) outlined the first legal provisions for public input and requires that the public be informed of impending decisions and provided an opportunity to provide input. The National Environmental Policy Act (NEPA, 1969) broadened public input requirements for actions with potential environmental impacts. Agencies must only hold hearings and go through notice and comment proceedings, although they are encouraged to consider additional avenues for public input.

The beginnings of public engagement governance are reflected in the Federal Advisory Committee Act (FACA, 1972), which regulates advisory committees that provide guidance to federal agencies. FACA provides for collaborative networks while ensuring that these networks function in the open, subject to public scrutiny. The Negotiated Rulemaking Act (NRA, 1996) furthers collaboration by allowing stakeholders to develop the content of proposed rules reached by consensus. Figure 1 illustrates the relationship between these laws and governance paradigms.

Newer policy and regulatory directives also have begun to include language that reflects public engagement. Examples include requirements for NEPA training in community-based planning and collaboration as well as regulations that encourage consensus building in the NEPA process (DOI Office of Environmental Policy and Compliance, 2010). DOI also developed an Adaptive Management Technical Guide to assist in decisionmaking under conditions of uncertainty, which requires stakeholder participation throughout the process (Williams, Szaro, \& Shapiro, 2007). Government-wide initiatives include directives to build capacity for collaborative problem solving (Office of Management and Budget and President's Council on Environmental Quality (CEQ), 2005) and the CEQ NEPA Collaboration Handbook (CEQ, 2007). Finally, the tenets of the current White House Open Government Initiative (http://www.whitehouse.gov/open), transparency, public participation, and collaboration, also reflect public engagement governance. This legal and policy framework indicates high-level support for the principles of public engagement governance, which, as previously mentioned, is not yet widely adopted by managers in day to day practice. Given this situation, we conducted a set of pilot interviews to help us develop a research agenda that would identify specific actions to improve the adoption of collaborative conservation more broadly throughout DOI agencies.

\section{Interview Methods}

To initiate this process, we focused on known public participation innovators as key informants on the state of agency practice. We conducted semi-structured informal interviews with ten practitioners and agency staff identified by the authors through previous research and professional experience. Interviews were conducted by telephone during normal business hours from May 10-August 6, 2010 and lasted approximately 45 minutes. Interviewees described their experiences with: best practices and agency practices for 
public participation; barriers to public engagement governance and ways to overcome them; the degree to which FACA committees were perceived to facilitate public engagement; and how public engagement might assist decision-making under conditions of uncertainty. Confidentiality was assured. Interviewees were employees or contractors of NPS, BLM, FWS, and US Institute for Environmental Conflict Resolution. Responses were considered individual, rather than agency, opinions. We audio-recorded interviews and wrote up notes in detail following the interviews. Questions were open-ended and structured to elicit spontaneous responses rather than ask about specific agency or government initiatives. We examined interview responses for common themes around each topic area to improve adoption of public engagement in agency practice.

\section{Interview Results}

Interviewees shared a public engagement philosophy (by design), yet they described very individualistic paths for reaching that endpoint. Some had formal training in public participation, whereas others had learned on the job as a collateral duty. Likewise, they did not draw from a standard set of resources. For example, many mentioned the International Association for Public Participation (IAP2, http://www.iap2.org), yet some had never heard of it. Some attended more closely to policy initiatives than others. In addition, differences in agency operations were mentioned as making it difficult to apply standards across agencies. As a result, interviewees had difficulty identifying best practices across DOI agencies.

They identified a number of needs to assist adoption of public engagement, including capacity to design engagement processes specific to desired outcomes. They offered diagnostic questions that could be used to this end, such as, "What information does the agency need from the public? How will that information be used? What is considered a 'successful' outcome? Is consensus required?" and indicated this type of analysis is underutilized and not standardized. They also had difficulty identifying a standard process for determining metrics of success, which often was related back to the need to clearly define objectives. In addition, they recognized the variation in background and ability of staff responsible for public participation, which could be addressed by training. They also observed that historic reliance on contractors to conduct public participation has diverted learning outside of agencies. Similarly, they identified a need for rewards and incentives for public engagement, both for internal staff and external stakeholders.

In terms of law and policy, interviewees generally believed that legal requirements are inadequate. Most believed that the now standard processes to comply with NEPA inhibit creativity and ability to implement public engagement best practices. While many thought FACA committees had the potential to foster collaborative conservation, they all cautioned that FACA committees could not substitute for involving the public at large. They identified benefits of FACA committees, such as gaining more detailed information and enhanced communication and relationships, but questioned whether the intensity of time and resources needed to set up a formal committee was commensurate to these gains. Some noted that stakeholder engagement processes that do not invoke FACA can still be effective and may be less resource intensive.

Overwhelmingly, interviewees described the biggest barriers as systems barriers; despite policy directives, public engagement is not yet integrated into agency culture as a standard operating procedure, resulting in a lack of resources needed to do it well. As one interviewee described, "Somehow it hasn't yet gelled. You can't do effective conservation without stakeholder involvement. But the agencies are not quite believing in it enough to let it happen yet." Another stated that "the barrier is agency belief. If they don't 
value the process, it doesn't happen." Several interviewees believed this barrier is rooted in agency culture based in traditional public input practices; staff may believe they are conducting an open dialogue with the public while the public may not interpret actions to be transparent. Some thought that adaptive management was an opportunity for a shift in agency culture; acknowledging and collaboratively working to reduce uncertainty changes the dynamic between stakeholders and managers, requiring agencies to let go of their role as decision-maker to treat the public as peers.

\section{Discussion}

While not intended to be a comprehensive overview of agency practice, this study surfaced a number of observations that warrant further attention. Interviewees' repeated call for a change in agency culture indicates that the public engagement governance model is still in the early adoption stage. The diffusion of innovations theory (Rogers, 1995) describes the spread of a new idea or technology throughout society. The innovation is first introduced and tested by innovators, then progresses through early adopters, early majority, late majority, and finally laggards (at which point the innovation has become a societal norm). From an organizational perspective, the public engagement model appears to represent an authority innovation, where the adoption of the innovation has been made by a few individuals in high positions of power (in this case, policy makers), rather than as a collective innovation made by consensus among the members of the organization (Rogers, 1995). However, the fact that innovators with disparate backgrounds and motivations are experimenting with collaborative conservation indicates that the public engagement governance model has potential to be adopted as a collective innovation.

Interviewees identified a number of areas that might facilitate collective innovation, namely: development of and access to a standard set of resources that can improve familiarity with the breadth of approaches to public participation, diagnostic tools to help identify objectives and pair them with appropriate process design and metrics of success, development of rewards and incentives for internal staff and external stakeholders, and a cost benefit analysis of when and how processes such as FACA committees improve public engagement outcomes.

Interviewees observed that the rise of adaptive management may be an opportunity to shift agency culture towards a norm of public engagement. Recognition of unknowns appeared to alter the power dynamic and necessitated relationship building based on honesty and trust. These observations indicate a paradox in adaptive management: acknowledging scientific uncertainty can make communication more difficult, especially when diverse stakes and interests are involved, yet this situation necessitates collaborative problem solving. Public engagement processes founded on mutual learning and two-way dialogue will be imperative in an era of global stressors, uncertain outcomes, and adaptive management.

Bingham and O'Leary (2006) observed that a comprehensive theory for collaborative management that pools knowledge from disparate fields is missing. This puts the new era of governance at a disadvantage to scientific management, where multiple fields of specialization share the common foundational lens of ecology and evolutionary biology. In the meantime, adoption of public engagement governance in natural resource management throughout DOI likely will be gradual. Policies embracing this approach indicate the beginning of this trend; however, to become widespread, this type of innovation must diffuse throughout the government structure, from policy makers, to field officers, and most importantly to the influential decision-makers at mid-levels who control funding and set rewards. 
Public input governance likely will continue to play an important role, but is less suited than public engagement to identifying and addressing the root causes of ill-structured natural resource issues facing today's managers.

\section{References}

Administrative Procedure Act, 5 U.S.C. 551 et seq. (1946).

Allen, G. M., \& Gould Jr., E. M. (1986). Complexity, wickedness and public forests. Journal of Forestry, 84(4), 20-24.

Ansell, C., \& Gash, A. (2008). Collaborative governance in theory and practice. Journal of Public Administration Research and Theory, 18(4), 543-571.

Bingham, L. B., Nabatchi, T., \& O'Leary, R. (2005). The new governance: Practices and processes for stakeholder and citizen participation in the work of government. Public Administration Review, 65(5), 547-558.

Bingham, L. B., \& O’Leary, R. (2006). Conclusion: Parallel play, not collaboration: Missing questions, missing connections. Public Administration Review, 66, 161-167.

Brunner, R. D., Steelman, T. A., Coe-Juell, L., Cromley, C. M., Edwards, C. M., \& Tucker, D. W. (2005). Adaptive governance: Integrating science, policy, and decision making. New York, NY: Columbia University Press.

Council on Environmental Quality (CEQ). (2007). Collaboration in NEPA: A handbook for NEPA practitioners. Retrieved from http://ceq.hss.doe.gov/ntf/Collaboration_in_NEPA_Oct_2007.pdf

de Burca, G. (2010). New governance and experimentalism: An introduction. Wisconsin Law Review, 2010(2), 227-238.

DOI Office of Environmental Policy and Compliance. (2010). Environmental Statement Memorandum No. ESM10-18 Procedures for Implementing Public Participation and Communitybased Training. Retrieved from http://oepc.doi.gov/ESM/ESM 10-18 (Procedures for Public Participation and Community-Based Training.pdf

Federal Advisory Committee Act, 5 U.S.C. App (1972).

Lachapelle, P. R., McCool, S. F., \& Patterson, M. E. (2003). Barriers to effective natural resource planning in a "messy" world. Society \& Natural Resources, 16(6), 473-490.

Lauber, T., Decker, D., \& Knuth, B. (2008). Social networks and community-based natural resource management. Environmental Management, 42(4), 677-687.

Layzer, J. A. (2008). Natural experiments: Ecosystem-based management and the environment. Cambridge, MA: The MIT Press.

Leong, K. M., \& Decker, D. J. (2009). Moving public participation beyond compliance: Uncommon approaches to finding common ground. George Wright Forum, 26(3), 23-39.

Leong, K. M., Decker, D. J., Lauber, T. B., Raik, D. B., \& Siemer, W. F. (2009). Overcoming jurisdictional boundaries through stakeholder engagement and collaborative governance: Lessons learned from white-tailed deer management in the U.S. In K. Andersson, E. Eklund, M. Lehtola, \& P. Salmi (Eds.), Beyond the rural-urban divide: Cross-continental perspectives on the differentiated countryside and its regulation (vol. 14, pp. 221-247). Bingley, England: Emerald Publishing Group.

National Environmental Policy Act, 42 U.S.C. 4321 et seq. (1969).

Negotiated Rulemaking Act, 5 U.S.C. 561 et seq. (1996).

Office of Management and Budget and President's Council on Environmental Quality. (2005). Memorandum on environmental conflict resolution. Retrieved from http://www.justice.gov/adr/ pdf/ombceqjointstmt.pdf

Rittel, H. W. J., \& Webber, M. M. (1973). Dilemmas in a general theory of planning. Policy Sciences, $4,155-169$.

Robertson, P. J., \& Choi, T. (2010). Ecological governance: Organizing principles for an emerging era. Public Administration Review, 70, S89-S99.

Rogers, E. M. (1995). Diffusion of innovations (4th ed.). New York, NY: Free Press. 
Sax, J. L. (1970). The public trust doctrine in natural resource law: Effective judicial intervention. Michigan Law Review, 68(3), 471-566.

Williams, B. K., Szaro, R. C., \& Shapiro, C. D. (2007). Adaptive management: The U.S. Department of the Interior technical guide. Washington, DC: Adaptive Management Working Group, U.S. Department of the Interior.

Wondolleck, J. M., \& Yaffee, S. L. (2000). Making collaboration work: Lessons from innovation in natural resource management. Washington, DC: Island Press. 